\title{
FISIOTERAPIA NA PREVENÇÃO E PROMOÇÃO EM SAÚDE NA POPULAÇÃO EM SITUAÇÃO DE RUA: UM RELATO DE EXPERIÊNCIA
}

\author{
Isabelle Riceto $^{1}$ \\ Jéssyca Passos \\ Jheniffer Leal dos Santos \\ Luiz Eduardo Nóbrega \\ Larissa Moller \\ Lais Marion Rodrigues Ullirsch \\ Juliana Karla Lopes Polo \\ Beatriz Aparecida de Carvalho Miguel \\ Eduardo Sassi Carocci \\ Ana Carolina Brandt de Macedo \\ Talita Gianello Gnoato Zotz \\ Ariani Cavazzani Szkudlarek \\ Rubneide Barreto Silva Gallo
}

RESUMO: Introdução: A população em situação de rua (PSR) é considerada um grupo populacional heterogêneo que possui em comum a pobreza extrema. A fisioterapia é uma ciência que estuda, diagnostica, previne e recupera distúrbios cinéticos funcionais, e promove saúde. Objetivo: demonstrar a atuação da Fisioterapia na promoção e prevenção de saúde para a População em Situação de Rua de Curitiba - PR. Método: Foram aplicados questionários de autopercepção de saúde e desenvolvidas 10 atividades, que incluiu estudo da temática, reconhecimento local e ações de promoção e prevenção de saúde voltadas às necessidades da PSR. Resultados: Totalizou-se 211 participantes, dentre estudantes e população em situação de rua e os principais desconfortos encontrados foram as dores em membros inferiores, dores em membros superiores, dores na coluna e dor inespecífica. As ações visaram melhorar esses desconfortos e foram avaliadas pela população entre boas e ótimas e trouxeram uma grande vivência aos estudantes. Conclusão: A PSR carece de cuidado e atenção e estes encontros proporcionaram aos acadêmicos uma aproximação e uma experiência da atuação inigualável da Fisioterapia junto a esta população.

Palavras- chaves: Pessoas em Situação de Rua; Fisioterapia; Assistência Integral à Saúde; Acolhimento.

\section{PHYSIOTHERAPY IN HEALTH PREVENTION AND PROMOTION IN THE POPULATION IN STREET SITUATION: A REPORT OF EXPERIENCE}

ABSTRACT: Introduction: The street population (PSR) is considered a heterogeneous population group that has extreme poverty in common. Physiotherapy is a science that studies, diagnoses, prevents and recovers functional kinetic disorders, and promotes health. Objective: to offer physiotherapeutic activities for health promotion and prevention, for PSR of Curitiba PR. Methods: Health self-perception questionnaires were applied and 10 activities were carried out, including a study of the theme, local recognition, and health promotion and prevention

\footnotetext{
${ }^{1}$ Universidade Federal do Paraná
} 
actions geared to the needs of PSR. Results: There were 211 participants, among students and street population, and the main discomforts were pain in lower limbs, pain in upper limbs, pain in the spine and non-specific pain. The actions aimed at improving these discomforts and were evaluated by the population between good and great and brought a great experience to the students. Conclusion: The RSP lacks care and attention and these meetings provided the academics with an approximation and an experience of the unparalleled performance of Physiotherapy in this population.

KEY WORDS: Homeless People; Physical Therapy; Integral health care; User Embracement.

Revista Extensão em Foco, nº 20, Jan./Jul. (2020), p. 71 - 85. 


\section{INTRODUÇÃO}

A população em situação de rua (PSR) é considerada um grupo populacional heterogêneo que possui em comum a pobreza extrema, em que utiliza espaços públicos como moradia e sustento, de forma temporária ou permanentes. Diversos são os motivos que levam estas pessoas a tais condições, como os vínculos familiares interrompidos ou fragilizados, desemprego, dependência química, entre outros (BRASIL, 2009).

Na Política Nacional para Inclusão Social da População em Situação de Rua, criada em 2008 e atualmente em reformulação, já prevê a garantia da atenção integral à saúde das pessoas em situação de rua e adequação das ações e serviços existentes, assegurando a equidade e o acesso universal no âmbito do Sistema Único de Saúde, com dispositivos de cuidados interdisciplinares e multiprofissionais (Ministério do Desenvolvimento Social e Combate à Fome, 2008).

Várias outras políticas públicas contemplam a PSR, e segundo Souza (2017) estas são organizadas nos eixos: não específico que refere-se à ampliação de acesso aos serviços convencionais, como Unidades Básicas de Saúde (UBSs), Unidades de Pronto Atendimento (UPAs) e Centros de Referência da Assistência Social (CRASs); e específico que é um eixo intersetorial, cria dispositivos específicos, como Consultórios na Rua (CRs), Centros POP, Unidades de Acolhimento Institucional (UAIs) e CAPS, que são parte integrante da RAPS.

No eixo específico, as Unidades Básicas de Saúde (UBS), que foram criadas a partir Política Nacional de Atenção Básica (2006), composta pela equipe mínima médico, enfermeiro, auxiliar de enfermagem ou técnico de enfermagem e agentes comunitários de saúde. Os Núcleos de Apoio a Saúde da Família (NASF) foram criados pelo Ministério da Saúde em 2008, com o objetivo de apoiar a consolidação da Atenção Básica no Brasil, ampliando as ofertas de saúde na rede de serviços, assim como a resolutividade, a abrangência e o alvo das ações (BRASIL, 2012), e neles podem contemplar a atuação do fisioterapeuta.

A estratégia Consultório na Rua, é um tipo de projeto de inclusão social, intersetorial que foi instituída pela Política Nacional de Atenção Básica, em 2011, e visa ampliar o acesso da população em situação de rua aos serviços de saúde, oferecendo, de maneira mais oportuna, atenção integral à saúde para esse grupo populacional (BRASIL, 2012). A equipe básica do consultório na rua, segundo o Departamento de Atenção Básica (DAB), conta com três modalidades, sendo a modalidade 1 (enfermeiro, psicólogo, assistente social e terapeuta ocupacional), modalidade 2 (agente social, técnico ou auxiliar de enfermagem, técnico em 
saúde bucal, cirurgião dentista, profissional de educação física e profissional com formação em arte e educação) e modalidade 3 (todos os profissionais da modalidade 2 mais o médico). Notase que não está incluído o fisioterapeuta em nenhuma das modalidades, o que dificulta a acesso da PSF a esse serviço.

Desta forma, observa-se que a Fisioterapia apesar de uma ciência da saúde que estuda, previne e trata os distúrbios cinéticos funcionais intercorrentes em órgãos e sistemas do corpo humano (COFFITO), ainda não faz parte do grupo de profissionais que prestam assistência direta a PSR, apesar da clara necessidade, de -um atendimento interdisciplinar, humanizado, igualitário e digno, como qualquer indivíduo, visando principalmente a prevenção doenças e disfunções ortopédicas, respiratórias, cardiovasculares, neurológicas e não somente a reabilitação destas, que já se encontram em níveis de complexidade mais alto, onerando os gastos com os serviços de saúde.

Diante disso, o objetivo deste trabalho foi demonstrar a atuação da Fisioterapia na promoção e prevenção de saúde para a População em Situação de Rua no município de Curitiba - PR.

\section{MATERIAIS E MÉTODOS}

A partir da disciplina de Habilidades Fisioterapêuticas na Promoção e Prevenção à Saúde, desenvolvida no quarto período do curso de Fisioterapia, da Universidade Federal do Paraná (UFPR), foi realizada uma parceria com a Acolhida Franciscana Bom Jesus dos Perdões, para os acadêmicos, sob supervisão docente, desenvolverem ações de promoção e prevenção de saúde voltadas às necessidades da PSR.

A Acolhida Franciscana Bom Jesus dos Perdões, proporciona vários serviços à população de rua, dentre eles falas formativas, rodas de conversa, oficina de teatro, espaço para higienização e chá da tarde oferecido todos os dias para aproximadamente 70 pessoas em situação de rua.

As atividades aconteceram durante o período de julho a dezembro de 2017 , sendo o primeiro mês destinado a realização de debates, rodas de conversas, campanhas e reconhecimento local e diagnóstico das principais necessidades da PSR, a fim de traçar propostas de ação específicas para esta população e assim a implementação das ações fisioterapêuticas de prevenção e promoção de saúde. E o último mês destinado a apresentação do produto final das atividades propostas.

Revista Extensão em Foco, nº 20, Jan./Jul. (2020), p. 71 - 85. 
As ações de prevenção e promoção da saúde da PSR foram realizadas mensalmente, às segundas-feiras após o chá da tarde na Acolhida Franciscana Bom Jesus dos Perdões e teve duração de 1 hora e 30 minutos. O fluxograma das atividades encontra-se na Figura 1.

Figura 1: Fluxograma de atividades.

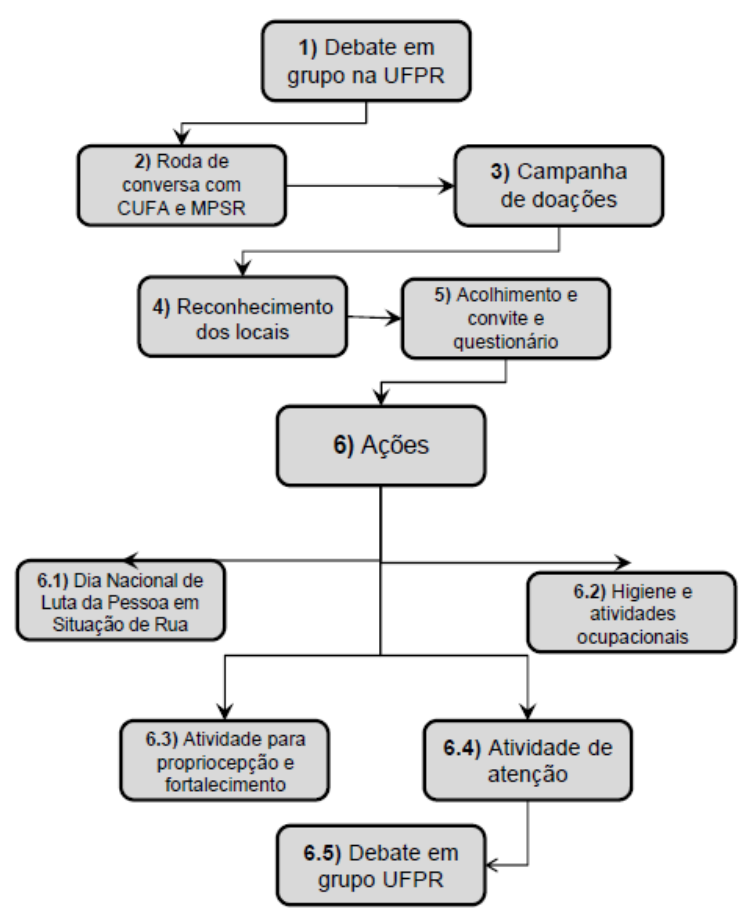

Fonte: Autores

1. Debate em grupo

O primeiro e o último encontro do grupo de estudantes ocorreu no campus da UFPR, com o intuito de debater sobre a percepção inicial e final dos estudantes frente às necessidades da PSR, a partir 4 questões abertas, levantadas pela docente responsável.

As questões abordadas e respondidas individualmente por cada estudante foram: 1 . “Quais os principais motivos que leva a uma pessoa a estar em situação de rua?”, 2. "Considerando o conceito amplo de saúde, quais são as necessidades desse grupo vulnerável específico e quais serviços de saúde eles têm acesso?”, 3. "O que você como futuro profissional de saúde pode contribuir e intervir na qualidade de saúde dessa população?" e 4. "Como você acha que a população em situação de rua vê o atual sistema de saúde quando tenta acessá-lo?”.

A partir das respostas iniciou-se o debate, baseado no que consta a literatura científica sobre a temática e ao final, relacionando-as com a experiência vivida.

\section{Roda de Conversa}

Revista Extensão em Foco, nº 20, Jan./Jul. (2020), p. 71 - 85. 
Na semana seguinte, baseada nas leituras recomendadas pela docente responsável e da participação de duas pessoas que vivenciaram a situação de rua, atualmente representantes da Central Única das Favelas (CUFA) e do Movimento Nacional da População em Situação de Rua (MNPR), aconteceu uma roda de conversa onde os mesmos tiveram a oportunidade de relatar suas experiências e esclareceram dúvidas dos acadêmicos.

3. Campanha de doações

A partir do conhecimento das necessidades particulares das pessoas em situação de rua, realizamos uma campanha de doações, durante todo o semestre de atividades, de produtos de higiene pessoal e roupas, via rede social, com o folder (FIGURA 2). Tais doações foram transformadas em Kits contendo (sabonete, xampu, creme, escova e pasta de dente, desodorante e absorvente) para serem distribuídos ao final das participações da PSR nas ações de promoção e prevenção, elaboradas pela fisioterapia e as roupas entregues a representante da CUFA/PR.

Figura 2: Folder de divulgação da campanha de doações.

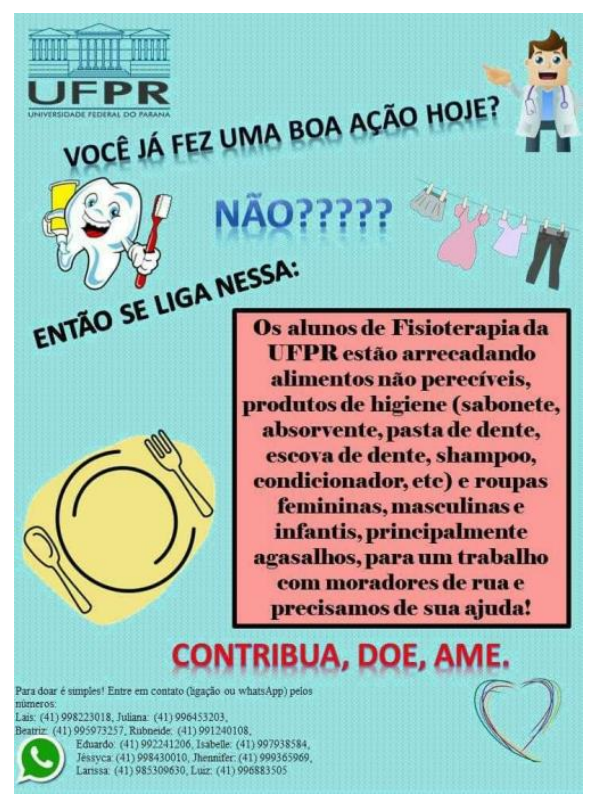

Fonte: Própria

4. Reconhecimento local

Foi realizada visita técnica no Consultório na Rua, vinculado a Secretária Municipal de Saúde e a casa de acolhimento chamada "Acolhida Franciscana Senhor Bom Jesus dos Perdões", que oferece chá da tarde a dezenas de pessoas em situação de rua. Apesar da tentativa de visita ao Centros POP, não obtivemos retorno da Fundação de Ação Social para realizada desta atividade.

Revista Extensão em Foco, nº 20, Jan./Jul. (2020), p. 71 - 85. 
5. Acolhimento, convite para participação das ações e diagnóstico das principais alterações físicas da PSR

Durante o chá da tarde, foi realizado o convite para todos participarem do Dia Nacional de Luta da População em Situação de Rua, em que a Fisioterapia iria participar oferecendo orientações para alívio de dor e desconfortos musculoesqueléticos. $\mathrm{O}$ acolhimento era realizado durante a distribuição do chá da tarde, em que os estudantes auxiliavam a servir e ao mesmo tempo convidava-os para uma avaliação prévia dos principais desconfortos apresentados por meio do questionário de autopercepção de saúde, elaborado pelo grupo de estudantes e para aferição dos sinais vitais no salão paroquial da igreja.

\section{Ações}

Antes e após as ações eram aferidas a Pressão Arterial e verificado a frequência cardíaca dos participantes.

6.1 Dia Nacional de Luta da População em Situação de Rua

Os estudantes de Fisioterapia foram convidados a participar deste evento promovido pelo MNPR realizado na Praça Rui Barbosa em Curitiba/PR no dia 18 de agosto de 2017.

A atividade consistiu de entrevistas com o questionário previamente elaborado sobre autopercepção de saúde, abordando principalmente questões relacionadas ao seu cotidiano e o impacto das mesmas sobre seu corpo e sua saúde e orientações individuais, a partir do folder educativo com alguns exercícios de alongamentos para prevenir futuras lesões e diminuir as dores presentes, e ao final da ação foram entregues os kits de higiene pessoal.

\subsection{Oficina de higiene e saúde ocupacional}

Foi realizada avaliação da ocupação dos participantes, pois apesar de muitos estarem em situação de rua, a maioria era vendedor em semáforo, catador de recicláveis, lavador de carro dentre outras. Além disso, o excesso de caminhadas, a temperatura, favorece a lesões e desconfortos diários.

A atividade iniciou-se roda de conversa sobre higiene e desconfortos ocupacionais, baseado no relato dos participantes, em seguida foi realizado alongamentos focado nos grupos musculares de membros superiores, membros inferiores e região cervical e relaxamento com exercícios respiratórios. E ao final da atividade, foram distribuídos kits de higiene e avaliação do atendimento. 
6.3 Oficina de propriocepção e fortalecimento muscular

A atividade começou com avaliação de equilíbrio e senso de posicionamento, em seguida, roda de conversa sobre a importância da propriocepção e do fortalecimento muscular, que se justifica pelo fato de estimular a sensibilidade proprioceptiva e melhorar o funcionamento da articulação, diminuindo o risco de ocorrências de lesões, juntamente com o programa de alongamentos e fortalecimento. A parte principal dos exercícios foram focadas na realização de um circuito com exercícios isométricos para membros inferiores e exercícios em solos para membros superiores e abdominais. Os exercícios de propriocepção, que consistia em: andar com os olhos vendados e seguir os comandas para qual direção virar, e outra em que todos de pé e seguir os comandos do examinador, por exemplo: “mão na cabeça, mão na cintura, gira para esquerda, abaixa”, esses comandos começaram de forma mais lenta e vão progredindo para rápido. Finalizando com a técnica de relaxamento, a lian gong, que é uma prática corporal e mental que utiliza o movimento, a respiração e a concentração com o intuito de promover relaxamento, equilíbrio e percepção corporal. Para finalizar, foi realizada uma reavaliação do equilíbrio e propriocepção, avaliação do atendimento e entrega dos kits de higiene.

\subsection{Oficina de atenção e concentração}

No último encontro com a PSR as atividades realizadas se basearam nos temas: "Higiene, saúde e exercícios" por meio de um jogo de perguntas e respostas, onde os participantes se dividiram em dois grupos, e cada grupo tinha o objetivo de acertar a pergunta. O outro tema era sobre "Como o estresse do cotidiano interferem em nossa memória e atenção", por meio do jogo "morto-vivo", desconcentrando os participantes com movimentos contrários; e um jogo de audição, onde um participante ficava sentado e vendado com um objeto a sua frente, e outro participante deveria pegar esse objeto sem que o outro participante escutasse. Para finalizar, com intuito de valorizar a população de rua foi entregue uma bexiga para cada participante que continha um papel com a frase "A arte da vida é a superação!".

\section{RESULTADOS E DISCUSSÃO}

Foram 10 encontros com temática relacionada a PSR, sendo a primeira etapa de estudo sobre a temática em questão e percepção dos estudantes frente as necessidades da PSR e na segunda etapa as ações realizadas para PSR.

\section{$1^{\text {a }}$ Etapa: Estudo temático e percepção dos estudantes frente as necessidades da PSR}

Revista Extensão em Foco, nº 20, Jan./Jul. (2020), p. 71 - 85. 
Na etapa estudo temático "População em Situação de Rua”, participaram estudantes $(n=9)$, docente $(n=1)$ e convidados $(n=2)$, totalizando 5 encontros sob a forma de metodologias ativas, que incluiu debates, a partir que questões norteadoras, pesquisa e leitura das políticas e artigos relacionados a PSR, rodas de conversa, com compartilhamento de experiências, reconhecimento dos locais de assistência a PSR, Campanhas de doações e o último encontro que foi um debate sobre a percepção final dos estudantes após as atividades realizadas na disciplina.

O debate em grupo ocorreu para verificar a percepção inicial dos estudantes frente às necessidades da PSR. Essa etapa contou com a presença de 9 estudantes e 1 professora, que mediou o debate através de um questionário. Na percepção inicial dos estudantes antes das ações: Questão 1. Os motivos que levam a pessoa a estar em situação de rua são as brigas familiares, divórcio, abandono familiar, desemprego, drogas e alcoolismo; Questão 2. As necessidades da PSR são saúde, higiene, alimentação, educação, saneamento básico e deveriam ter acesso a todos os serviços de saúde; Questão 3. O profissional de saúde poderá contribuir na qualidade de vida da PSR, oferecendo orientações voltadas a saúde e higiene dessas pessoas, bem como orientar a respeito de seus direitos enquanto cidadãos; Questão 4. A PSR vê o atual sistema de saúde ruim quanto tenta acessá-lo, principalmente pelo preconceito.

Em seguida, houve a roda de conversas, que contou com a participação de 9 estudantes, 1 professora, 1 representante do MNPR, e uma representante da CUFA. Essa roda, teve como objetivo esclarecer, tirar dúvidas e compreender a realidade da população em situação de rua e seus desafios. A partir dos relatos, pôde-se perceber que a predominância de problemas presentes na PSR são nos pés e articulações, escaras, queimaduras na pele, tuberculose, entre outros.

Com produto dessa roda de conversa, voluntariamente os estudantes realizaram uma campanha de doações, para arrecadar roupas e artigos de higiene para fazer doações ao final das atividades. Houve participação de 57 pessoas nas doações, e a partir delas foram montados 144 kits contendo xampu, sabonete, escova de dente e creme dental, e alguns com absorventes para a mulheres em situação de rua, que foram entregues após as oficinas.

Após estudo individual, debate coletivo e escuta aos relatos de experiência, foi feito o reconhecimento dos locais que assistem a PSR, visita ao Consultório na Rua e, então, o primeiro contato direto com a PSR, que foi na Acolhida Franciscana Bom Jesus dos Perdões, em um chá da tarde que contava com a presença de 70 pessoas em situação de rua. Nesse momento, os estudantes auxiliaram na entrega do chá, almoço e após aferiram pressão, e aplicaram um Revista Extensão em Foco, nº 20, Jan./Jul. (2020), p. 71 - 85. 
questionário sobre a autopercepção de saúde. E ao final foi realizada discussão sobre para verificar a percepção final dos estudantes frente às necessidades da PSR.

Na percepção final dos estudantes após as ações: Questão 1. Os motivos que levam a pessoa a estar em situação de rua de fato são as citadas anteriormente, sendo as drogas as mais referidas pelos participantes; Questão 2. As necessidades da PSR também se mantêm, como saúde, higiene, alimentação, educação, saneamento básico e gostariam de ter acesso a todos os serviços de saúde, mas o maior desejo relatado é sair das drogas e ter uma moradia digna para refazer os laços familiares; Questão 3. O profissional de saúde poderá contribuir em vários aspectos relacionados às várias doenças, mais comuns relatadas, Doenças Sexualmente Transmissíveis, como HIV, relatados por alguns, Doenças Infectocontagiosas, como a tuberculose, pneumonias, psíquico-sociais, mais comuns a drogadição, os emocionais, a presença da depressão, vinculada ao afastamento da família e o preconceito e os aspectos físicos como consequências das brigas, maus tratos sofridos e da própria situação que se encontram, andam bastante em busca de comida, de um lugar para dormir, enfrentando as alterações climáticas, carregam muito peso, com os poucos pertences que possuem. Assim, todos os profissionais não somente da saúde, mas todo o cidadão tem o dever de respeitar e contribuir para melhores condições de vida da PSR; Questão 4. A PSR vê uma desvalorização da Política Brasileira voltada a essa população, principalmente pelo preconceito sofrido, mas destacam também que apesar da ajuda de alguns órgãos públicos, poucos aderem o tratamento e relatando o quanto é difícil sair das drogas e o quanto a rua é acolhedora. E por estarem por muitos anos nesta vida, ter um convívio social ainda é difícil.

\section{$2^{\text {a }}$ etapa: Ações de prevenção e promoção da saúde para PSR}

As ações fisioterapêuticas foram planejadas e aplicadas pelos acadêmicos $(n=9)$, sob supervisão docente $(n=1)$ e todas voltadas a Prevenção e Promoção da Saúde da PSR. Foram realizadas em 5 encontros diretamente com a PSR, iniciando com o acolhimento, convite para participação das atividades, avaliação das necessidades da PSR e as ações e contou com a participação de $n=144$ PSR, sendo apenas $n=15$ mulheres. Os resultados das atividades estão expostos na tabela 1 .

Tabela 1: Panorama das atividades realizadas com a População em Situação de Rua, os resultados e impactos destacados. 


\begin{tabular}{|c|c|c|c|}
\hline Temática & Objetivo & Participantes & Resultados \\
\hline $\begin{array}{l}\text { Acolhimento, } \\
\text { convite para o Dia } \\
\text { Nacional de Luta } \\
\text { da População em } \\
\text { Situação de Rua e } \\
\text { aplicação de } \\
\text { questionário de } \\
\text { autopercepção as } \\
\text { saúde. }\end{array}$ & $\begin{array}{l}\text { Obter o primeiro } \\
\text { contato com a } \\
\text { população, } \\
\text { convidá-los para o } \\
\text { dia de luta e } \\
\text { identificar as suas } \\
\text { principais queixas } \\
\text { musculoesquelética }\end{array}$ & $\begin{array}{l}\mathrm{n}=70 \quad \text { PSR } \\
\text { convidados } \\
\text { (chá da tarde) } \\
\mathrm{n}= \\
\text { entrevistas } \\
\text { (homens) }\end{array}$ & $\begin{array}{l}\text { A maioria dos participantes do } \\
\text { chá da tarde é do sexo } \\
\text { masculino. Somente } 8 \text { deles } \\
\text { com média de } 35 \text { anos de idade } \\
\text { responderam o questionário de } \\
\text { autopercepção, } 2 \text { pessoas } \\
\text { classificaram a saúde como } \\
\text { regular a muito boa e os outros } \\
6 \text {, como muito ruim ou ruim. } 5 \\
\text { deles tem dificuldades de } \\
\text { deambulação e todos relataram } \\
\text { dores em pelo menos uma das } \\
\text { áreas a seguir: pernas, pés, } \\
\text { coluna e ombros. }\end{array}$ \\
\hline $\begin{array}{l}\text { Dia Nacional de } \\
\text { Luta } \\
\text { População em } \\
\text { Situação de Rua }\end{array}$ & $\begin{array}{l}\text { Identificar as } \\
\text { principais } \\
\text { disfunções } \\
\text { musculoesquelética } \\
\text { s da PSR e oferecer } \\
\text { orientações para } \\
\text { melhoria dos } \\
\text { desconfortos. }\end{array}$ & $\begin{array}{l}\mathrm{n}=30 \\
\text { entrevistas e } \\
\text { orientações }\end{array}$ & $\begin{array}{l}\text { Participaram } 15 \text { PSR sexo } \\
\text { masculino e } 15 \text { sexo feminino, } \\
\text { com média de idade de } 38 \text { anos. } \\
\text { Os desconfortos } \\
\text { musculoesqueléticos } \\
\text { apresentados: } 12 \text { relataram } \\
\text { dores em MMII, } 2 \text { dores em } \\
\text { MMSS, } 3 \text { dores na coluna, } 1 \text { dor } \\
\text { inespecífica e } 12 \text { nenhuma dor. }\end{array}$ \\
\hline $\begin{array}{l}\text { Atividade sobre } \\
\text { higiene e doenças } \\
\text { ocupacionais }\end{array}$ & 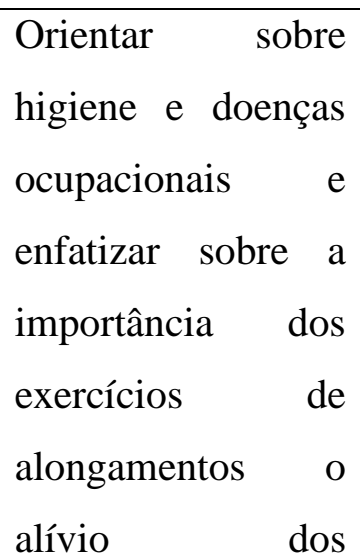 & $\mathrm{n}=10$ & $\begin{array}{l}\text { Todos os participantes do sexo } \\
\text { masculino com idade média de } \\
38 \text { anos, maioria catadores de } \\
\text { materiais recicláveis. Todos } \\
\text { participaram da atividade, } 4 \\
\text { participantes relataram alívio de } \\
\text { dores com os alongamentos e os } \\
\text { outros } 6 \text { não fizeram relatos. }\end{array}$ \\
\hline
\end{tabular}

Revista Extensão em Foco, nº 20, Jan./Jul. (2020), p. 71 - 85. 


\begin{tabular}{|c|c|c|c|}
\hline & $\begin{array}{l}\text { desconfortos } \\
\text { relatados pela PSR. }\end{array}$ & & \\
\hline $\begin{array}{l}\text { Atividade para } \\
\text { propriocepção e } \\
\text { fortalecimento }\end{array}$ & $\begin{array}{l}\text { Estimular } \\
\text { percepção corporal, } \\
\text { o equilíbrio e } \\
\text { prevenir possíveis } \\
\text { dores } \\
\text { programa } \\
\text { alongamento } \\
\text { fortalecimento }\end{array}$ & $\mathrm{n}=14$ & $\begin{array}{l}\text { Todos os participantes do sexo } \\
\text { masculino e a maioria } \\
\text { demonstrou interesse sobre o } \\
\text { assunto retirando dúvidas sobre } \\
\text { qual o melhor exercício para } \\
\text { alívio de sua dor. Foi avaliado } \\
\text { ao equilíbrio estático antes e } \\
\text { após a atividade e foi possível } \\
\text { identificar melhora em } 8 \text { dos } \\
\text { participantes. }\end{array}$ \\
\hline $\begin{array}{lr}\text { Atividade } & \text { de } \\
\text { atenção } & \text { e } \\
\text { concentração } & \end{array}$ & $\begin{array}{l}\text { Conscientizar sobre } \\
\text { a importância da } \\
\text { higiene, saúde e } \\
\text { exercícios; e avaliar } \\
\text { a atenção dos } \\
\text { participantes. }\end{array}$ & $\mathrm{n}=12$ & $\begin{array}{l}\text { No jogo de perguntas e } \\
\text { respostas, foram realizadas } 10 \\
\text { perguntas, das quais } 9 \text { foram } \\
\text { respondidas corretamente pelos } \\
\text { participantes. O jogo do "morto- } \\
\text { vivo" foi realizado para que os } \\
\text { participantes percebessem } \\
\text { como a atenção ocorre, seguido } \\
\text { da brincadeira da audição, onde } \\
\text { nenhum dos participantes } \\
\text { conseguiu se atentar ao barulho } \\
\text { do próximo. }\end{array}$ \\
\hline
\end{tabular}

Fonte: Dados dos autores (2017)

Ao final de cada encontro, foi entregue aos participantes uma escala de avaliação da atividade, a qual era constituída por faces com expressões que caracterizam a atividade como não recomendada, ruim, regular, bom ou ótimo. Em todas as atividades, as marcações na escala se dividiam em bom e ótimo, demonstrando que a percepção da PSR frente às ações da fisioterapia foi bastante positiva.

A saúde é concebida não somente como ausência da doença, mas sim, como uma "situação de perfeito bem-estar físico, mental e social" (OMS), ou seja, deve contemplar Revista Extensão em Foco, nº 20, Jan./Jul. (2020), p. 71 - 85. 
alimentação, educação, renda, trabalho, emprego, lazer, etc. Diante disso, a Constituição Federal de 1988 prevê direito à saúde a todos os cidadãos. Porém, isso está longe de contemplar a população em situação de rua, pois muitas vezes ficam em uma posição de invisibilidade, sendo destituídos por parte da sociedade os seus direitos como cidadãos (AGUIAR e IRIART, 2012).

As necessidades básicas de todo ser humano envolvem: alimentação, higiene e necessidades fisiológicas (roupas e abrigo). A população em situação de rua encontra-se privada disso, pois estão na rua devido a diversos motivos e não possuem uma renda para alimentação, abrigo e higiene. Por isso, muitas vezes, esse grupo é visto e lembrado como "pessoas sujas, fedorentas, roupas rasgadas". Este preconceito não atinge somente o físico da PSR, mas muitas pessoas sentem medo, pois os vêem como criminosos. A maior parte dessas pessoas sobrevive com a solidariedade de pessoas, que os ajudam dando moedas, roupas e alimentos. Mas isso ainda não supre as necessidades que um ser humano requer (COSTA, 2005).

Os relatos recebidos em nossas atividades, sobre a visão da sociedade a respeito das pessoas em situação de rua corroboram com os depoimentos presentes no artigo de Mattos et al (2004). Um destes depoimentos relata o medo das pessoas em se aproximar desta população na rua, como se pudessem levar um choque. Este medo é relacionado com o estigma da PSR como criminosos e perigosos, e em todas atividades realizadas pelo presente estudo foram recebidos relatos sobre essa visão de perigo, um deles foi: "achei legal vocês fazerem isso, a maioria das pessoas não querem nem chegar perto de nós". Ao término do estudo foi constatado que realmente leva-se um choque ao se aproximar da PSR, um 'choque' de desigualdade e desumanização do homem na sociedade

Segundo o Manual Técnico do Ministério da Saúde, sobre o cuidado à saúde da população em situação de rua, as doenças que mais afetam essa população são: problemas nos pés, pediculose, escabiose, tuberculose, DSTs (HIV e AIDS), hepatites virais, doenças crônicas (hipertensão, diabetes, e Doença Pulmonar Obstrutiva Crônica - DPOC). Além disso, há a questão da gravidez que também se torna um problema, principalmente porque tratam-se de mulheres que, em sua maioria, são dependentes químicas - tanto de drogas ilícitas quanto de álcool -, desnutridas ou que possuem doenças infectocontagiosas (BRASIL, 2012). Tais dados divulgados pelo Ministério da Saúde corroboram em parte com o encontrado na presente pesquisa, onde as dores nos pés e membros inferiores em geral são bastante citadas pelos participantes.

Revista Extensão em Foco, nº 20, Jan./Jul. (2020), p. 71 - 85. 
Em países em desenvolvimento como o Brasil, há uma alta incidência do câncer de pênis. Sendo mais comuns em pessoas com baixo nível socioeconômico, com maus hábitos de higiene íntima e pode estar associado com a infecção pelo Papiloma vírus humano - HPV (REIS, 2010). Nas atividades com a PSR, quando questionados acerca do câncer de pênis, DST's e infecção pelo HPV, poucos participantes tinham conhecimento sobre o assunto. Assim, a educação e a promoção em saúde se tornam fundamentais para esta população para prevenção de riscos, tais como os citados acima.

Sobre os problemas físicos na PSR, não foram encontrados estudos na literatura científica, no entanto, na presente pesquisa observou-se que as dores musculoesqueléticas, estão relacionadas aos membros inferiores. E apesar de Nava (2012), não ter realizado sua pesquisa com a PSR, e sim com coletores de material reciclável e varredores de rua, verifica-se a relação com os resultados desta pesquisa, pois muitos deles também realizavam tais funções, referindo queixas em membros inferiores. Ambos grupos exercem atividades que requerem caminhadas por um longo período de tempo, outras atividades que utilizam muitos os membros superiores e a sobrecarga na coluna vertebral.

Diante de todo o tempo e todas as ações realizadas com a PSR, as maiores limitações encontradas neste trabalho ocorreram devido a impossibilidade de manter um grupo fixo para as atividades, visto que a cada dia de ação, haviam diferentes pessoas, tornando difícil acompanhar a evolução e possível melhora causada pelas atividades. Porém, mesmo com estas dificuldades, a experiência inovadora acrescentou muito, na maneira de pensar e de agir, e que com certeza será muito significativo tanto para a vida profissional quanto pessoal.

\section{CONCLUSÃO}

A PSR carece de cuidado e atenção por parte da sociedade e dos profissionais da saúde, devendo receber um tratamento humano e igualitário. Diante disso, os encontros realizados proporcionaram aos estudantes uma experiência da atuação inédita da Fisioterapia com esta população, bem como uma atenção recíproca desta população as atividades propostas.

\section{AGRADECIMENTOS}

Agradecemos a Acolhida Franciscana Bom Jesus dos Perdões, por ceder o espaço para a realização das atividades e por prestarem toda a ajuda e suporte. E a todas as pessoas que aderiram à nossa campanha de doação e ajudaram com artigos de higiene e roupas para a PSR. 


\section{REFERÊNCIAS}

AGUIAR, M. M.; IRIART, J. A. B. Significados e práticas de saúde e doença entre a população em situação de rua em Salvador, Bahia, Brasil. Cad. Saúde Pública, Rio de Janeiro, 28(1):115-124, jan, 2012.

BRASIL. Ministério da Saúde. Manual sobre o cuidado à saúde junto à população em situação de rua. Brasília. 2012. Disponível em: <http:saúde.gov.br/dab/docs/publicacoes/geral/manual_cuidado_populalcao_rua.pdf.>. Acesso em 24 nov. 2017.

BRASIL. Ministério da Saúde. Secretaria de Atenção à Saúde. Departamento de Atenção Básica. Política nacional de atenção básica / Ministério da Saúde, Secretaria de Atenção à Saúde, Departamento de Atenção à Saúde. - Brasília : Ministério da Saúde, 2006.

BRASIL. Decreto nº 7.053, de 23 de dez. de 2009. Brasília, DF, dez 2009.

BRASIL. Ministério da Saúde. Consultório na Rua. Brasília: Departamento de Atenção Básica, 2012. Disponível em: 〈http://dab.saude.gov.br/portaldab/ape_consultorio_rua.php>. Acesso em: 30 nov. 2017.

BRASIL. Ministério da Saúde. Núcleo de Apoio à Saúde da Família (NASF). Brasília: Departamento de Atenção Básica, 2012. Disponível em: <http://dab.saude.gov.br/portaldab/ape_nasf.php>. Acesso em: 30 nov. 2017.

COSTA, A. P. M. População em situação de rua: contextualização e caracterização. Revista Virtual Textos \& Contextos, $\mathrm{n}^{\circ}$ 4, dez. 2005.

COFFITO. Conselho Federal de Fisioterapia e Terapia Ocupacional. Fisioterapia. Disponível em: <https://www.coffito.gov.br/nsite/?page_id=2341>. Acesso em: 30 nov. 2017.

MATTOS, R.M.; FERREIRA, R.F. Quem vocês pensam que (elas) são? Representações sobre as pessoas em situação de rua. Psicologia \& Sociedade; 16 (2): 47-58; maio/ago,2004.

NAVA, V. S. A ocorrência de sintomas osteomusculares em coletores de lixo e varredores de rua de um município da região metropolitana de campinas. Dissertação de Mestrado apresentada à Pós Graduação da Faculdade de Ciências Médicas Da Universidade Estadual de Campinas - UNICAMP. Campinas, 2012.

REIS, A. D. S; PAULA, L. B; PAULA, A. A. P; SADDI, V. A; CRUZ, A. D. Aspectos clínicoepidemiológicos associados ao câncer de pênis. Rev. Ciência \& Saúde Coletiva. v.15, Suppl. 1, p. 1105-1111, 2010.

SOUZA, C. S. Significados da rede de atenção psicossocial para pessoas em situação de rua em tratamento de álcool e outras drogas em Curitiba. Dissertação (Mestrado) Universidade Tuiuti do Paraná, Curitiba, 2017. 